\title{
Writing and Identity: A Narrative Inquiry on Two Saudi Arabian ESL Females
}

\author{
Mustafa A. Hersi ${ }^{1}$ \\ ${ }^{1}$ King Abdulaziz University, Saudi Arabia \\ Correspondence: Mustafa A. Hersi, King Abdulaziz University, Saudi Arabia.
}

Received: July 23, 2021

Accepted: August 27, 2021

Online Published: August 30, 2021

doi: 10.5539/elt.v14n9p48

URL: https://doi.org/10.5539/elt.v14n9p48

\begin{abstract}
Writing in a second language is considered extremely challenging for several reasons. Concerns that perplex second-language learners include cognitive complications, the composing process, building arguments, and constructing an identity as a writer. Cultural issues related to writing also pose problems for second-language writers This paper focuses exclusively on how international students, female Saudi ESL students, construct their writing identity in the ESL milieu and navigate critical issues in cross-cultural writing. This paper explores how two ESL Saudi Arabian female students in an English program in the United States negotiate and construct their identities while writing in English. The study will also investigate challenges faced by those students in acquiring English writing skills and how those challenges inform their thinking and shape or reshape their identities as writers.

The study involves two female Saudi students who are studying the English language at a mid-size diverse Southwest public university in the United States. The researcher collected the data through semi-structured interviews with the participants and then performed a textual analysis of their responses. The researcher transcribed and analyzed the data and describes the results thematically herein. The findings of this study augment our understanding in how female Saudi ESL students construct their identities as writers. The analysis covers some sociocultural factors that shape their writing. The paper concludes with pedagogical implications for ESL teachers and suggestions for future study.
\end{abstract}

Keywords: identity, academic writing, construction of identity, narrative voice, cultural forms of capital

\section{Introduction}

Writing, as a complex sociocultural process, plays a vital role in our personal, academic, and professional lives. Many studies on scholarly writing and identity in English for second-language learners have addressed the need for instructors to scaffold international students so that they may acquire "a voice or identity in their writing" (Hervd \& Belcher, 2001). It has been argued widely that international students in Western-based academic writing classrooms possess different form of intellectual capital, including linguistic, cultural, and social capital. These forms of capital should not be marginalized (Canagarajah, 2000). Instead, they should be seen by researchers as valuable additions to academic discourse. These international student writers often bring their first-language writing habits and discourses to the English-language writing classroom. These habits and discourses should be regarded as resources by their professors. To date, however, few studies have specifically explored and documented the ways in which linguistic, social, and cultural peculiarities brought to the classroom by international ESL students have been regarded as resources or marginalized in Western-based academic writing classrooms. This study uses Bourdieu's (1986) form of capital as a conceptual framework to explore and document "the discoursal construction of identity in academic writing" (Canagarajah, 2000) in the life of two female Saudi ESL students studying at a Western-based university. It focuses exclusively on how these women resist, negotiate, and construct their identity as writers in their ESL program. I conclude with a discussion of negotiating pedagogies in writing, language, race, capital, and identity construction in Western-based ESL training programs.

Whenever Islamic or Arabic cultural issues are discussed in life in general and in academia in particular, women's rights often emerge as an issue. Women's rights have been one of the most contentious and misrepresented topics for a long time in Arabic and Islamic culture. Debates have included issues of the veil, polygamy, driving, women's education, and women's voices. Unfortunately, many academic discourses have been negative or have 
neglected women's true concerns. Few studies have been carried out about women's education in the Arab world, especially in Saudi Arabia. Religious and cultural knowledge are essential pieces of women's lives in Saudi Arabia, and they have fueled my interest in helping Saudi women's voices to be heard.

In Arabic culture, women's role lies largely on carrying out household chores: cooking, cleaning the house, raising children, and taking care of one's husband are among the most important responsibilities of women. The traditional role of men is to work to provide for the needs for their family. However, women have challenged this construction of men's and women's roles. Women's roles and contributions to society vary based on time, place, and sociopolitical environment. Many tribal, traditional, and cultural issues have been intertwined with religious guidelines. Various ideologies, sociocultural factors, and sociopolitical notions in the Arab world have kept women's issues from receiving the attention that they deserve. This study delves into one of the misconstrued issues: women's education in Saudi Arabia.

As have many other women in different parts of the world, Saudi women have become empowered to assert their rights and exercise them. For example, girls and women were excluded from education in Saudi Arabia until the government established female public schools in 1956 in various part of the kingdom. Before then, only a few female students, most of them from rich families, were educated at home by private tutors or sent abroad to study in Egypt or Lebanon. Since then, the number of male and female students continued to climb. There were about 7,000 male and female students enrolled in institutions of higher education in Saudi Arabia 1970. That number surpassed one million students in the academic year 2013/2014.

The increase of oil prices in the last few years generated economic growth in Saudi Arabia that has been used to improve the educational system a great deal. The changes experienced by the educational system in Saudi Arabia in the past decade are unprecedented. The government has invested billions of dollars in education and encouraged male and female students to pursue their studies overseas. The King Abdullah Scholarship Program was launched in 2005 as a political initiative e between Saudi Arabia and the United States to help young Saudis to pursue education in the United States. Opportunities were created for both male and female Saudis, and the number of Saudi students studying in the United States universities and colleges in 2014 exceeded 106,000. The hope was that they would return to Saudi Arabia to enter key leadership positions in the private and public sectors.

This paper is divided into four parts. The first part provides an overview of the problem, background, the purpose of the study, the significance of the study, and the research questions. The second part presents a literature review on the topic. The third part presents the theoretical framework and the methodological approach used in this study. The fourth part is comprised of two sections: the first summarizes the data analysis, while the second discusses findings and pedagogical implications. The main questions addressed in this paper are:

1) How do female Saudi students construct their identities as writers in an American university?

2) What challenges do female Saudi students face in writing in an American university?

\subsection{Statement of the Problem}

International students in the United States encounter many cultural and linguistic challenges. Some of these difficulties are apparent, while others are obscure. As a result of my experience as an international student in two American universities and as the father of two female students currently enrolled in high school in an American charter school, I am drawn to investigate how Saudi students fare in studying in an ESL context in the U.S.

"Language is by no means the only tool of mediating identity in different contexts, a point that could have received more attention" (Chamcharatsri, 2010, p. 210). In recent years, social science and second-language acquisition (SLA) scholars have shown great interest in investigating second language learners' identities. "The relationship between language and identity is an intriguing one, partly because debates on theories of language are as inconclusive and indeterminate as debates on theories of identity" (Norton, 2018). The purpose of the present study is to examine how two Saudi Arabian female ESL students negotiated and constructed their identities as writers. This study also explores the challenges that these women encountered in learning English-language writing skills. Identity studies have been conducted in different contexts and through various lenses. "Identity is a complex multilayered construct. It is also a construct that has tended to be examined from particular perspectives by theorists and researchers" (Block, 2009, p. 32). Most studies in second-language learners' identity have only been carried out among Asian students (Hsieh, 2008; Min-Hua, 2006; Morita, 2004). A few research studies have investigated how female Saudis negotiated and constructed their identities as they acquire English, especially as they acquire writing skills. However, there has been little discussion about how Female Saudi ESL students construct their identities as writers. This study is intended to address this gap in the 
research. This study investigates how Saudi women construct their identity as writers in an English-as-a-second language (ESL) milieu.

\subsection{Purpose of the Study}

As result of my personal experience as a parent of two teen female students in an American high school, I was drawn to investigating how women construct their identity as academic writers in an ESL context. The purpose of this study is to investigate how two ESL Saudi Arabian female students in an English program in the United States negotiated and constructed their identities while writing in English. The study also investigated challenges faced by those students in acquiring English writing skills and how that shaped their thinking and their identities as writers.

\subsection{Significance of the Study}

What follows are the most significant insights generated from this research study. The present study examined female Saudi students, so it seems relevant to explore Saudi students' previous academic experience, especially the great discrepancies between Saudi Arabia and the United States educationally, culturally, linguistically, socially, and religiously. The number of Saudi students studying in the United States has been increasing exponentially. The Saudi Arabian Cultural Mission in the USA (SACM) has reported that the number of Saudi male and female studying in American colleges and universities exceeded 116,000 students, yet few studies have explored the experiences of Saudi students in those colleges and universities. Although the Saudi government has encouraged Saudi males and females to pursue their studies in North American colleges and universities, most Saudi scholarships for such studies have gone to the Saudi males. Little discussion about female Saudi students has been documented. This study was conducted to bridge the gap that exists in the literature.

This study was intended to better understand the educational experience of Saudi women in U.S. universities as they constructed their identities as writers in an ESL context. This study gave two Saudi women a chance to tell their stories. The second research question of this study addressed the challenges that female Saudis face when they write academically in English, so this study should help increase understanding of female Saudi students' personal and professional needs in developing their ESL writing skills. Finally, this study supplies pedagogical applications to instructors in the field of teaching English to speakers of other languages (TESOL) and to ESL teachers in particular.

\subsection{Research Questions}

The purpose of this study was to investigate how two ESL Saudi Arabian female students in an English program in a university in the United States negotiated and constructed their identities as writers of English. The study also investigated the challenges that these students faced in acquiring English writing skills and how that informed their thinking and shaped their identities as writers.

The primary research questions were:

1) How do female Saudi students construct their identities as writers in an American university?

2) What challenges do female Saudi students face in writing in an American university?

To investigate the topic, I narrow the topic to the most important questions. These questions were used to gather data through semi-structured questionnaires used with the two participants. Follow-up questions are discussed below in the methodology section.

\subsection{Strengths and Limitation of the Study}

The strength of this qualitative research relies on the design of the study. In-depth semi-structured questionnaires were used in interviews conducted with the participants in their native language, Arabic. Participants were given the choice to speak whichever language they chose: Arabic (L1) or English (L2). Although both participants preferred to be interviewed in English, one of the participants switch-coded to convey certain thoughts and concepts in some parts of her narrative. I let the interviewees use L1 to express themselves whenever they preferred to do so.

Another strength of this research is that the findings add contributions to the limited literature about Saudi students in general and female Saudis in particular. Furthermore, giving Saudi women a safe venue to express their voices and tell their stories was the major strength of this study. Their narratives shed light on how to empower international students in general and Saudi women in an ESL context in particular. The study's proposed pedagogical implications for ESL instructors could help improve their instruction. 
Several caveats need to be noted regarding the present study. The sample size was only two participants. Another limitation is that the study aimed to investigate one type of population, female Saudi Arabian ESL students in an American ESL context. The research was designed to explore only female Saudi ESL students. If the study had been designed to include male Saudi students, it could have documented different experiences and yielded different results.

\subsection{Definition of Identity}

In the field of teaching English to speakers of other languages (TESOL), various definitions of identity have been used. For example, Norton (2018) defined the term "identity" as "how people understand their relationship to the outside world, how that relationship is constructed across time and space, and how people understand their possibilities for the future" (p. 410). Schmitt (2002) defined identity as "an important social factor. Not only do linguistic patterns signal social and individual identity, but also people's conscious awareness of their personal, ethnic, geographical, political, and family identities is often a factor in their language use. In this paper, Norton's definition of identity is used.

\section{Literature Review}

This review of literature is divided into three sections. The first section highlights the educational context of Saudi Arabia, which is the cultural background of the participants in this study. In the second section, I review the history of women's education in the Kingdom of Saudi Arabia. Finally, I examine the contexts and perspectives of a number of studies on identity, academic writing, and constructing one's voice.

\subsection{Education in Saudi Arabia}

Education in Saudi Arabia from primary school through high school is free of charge to all Saudi citizens and expatriates who want it. There are three stages in Saudi education. The first stage is primary education, which is for students from six years of age to twelve years of age. The second stage is junior high school, which is for students from thirteen to fifteen years of age. The third stage is high school, which is for students from sixteen to eighteen years of age. The Saudi Arabian government has been increasing its spending on education and has opened many new schools in the last three decades. The Saudi Ministry of Education (2014) stated that the number of students enrolled in primary school in Saudi Arabia was 1,266,266; in junior high school, 1,230577 students were enrolled; and in high school, 543,886 students were enrolled. The total number of students enrolled in Saudi Arabian public and private schools was 3,995,627.

\subsection{Women's Education in Saudi Arabia}

In 1959, King Saud Bin Abdul-Aziz created a milestone in education in Saudi Arabia. He made a speech to announce the establishment of the first formal public education for females in the kingdom. In that speech, the king laid down many crucial and controversial issues in female education. For example, he announced that female education would be under his own supervision and care (Prokoo, 2003). In1960, the Kingdom of Saudi Arabia initiated women's education. Before that time, there was no formal public education for women in the kingdom. However, there were a few private schools for women, scattered mainly in the western part of the kingdom, especially in the holy city of Makkah. These schools concentrated on teaching the Holy Quran and other religious subjects. Furthermore, females from rich families were in a better position than other female citizens because many females from rich families were either educated at home or sent to private schools outside the country.

The Ministry of Higher Education in Saudi Arabia was established in 1975 to supervise, coordinate, and develop public and private higher education in the country. It also has encouraged Saudi citizens to specialize and develop their knowledge and skills in all fields, including administration, the social sciences, and hard sciences (Ministry of Higher Education, 2014). The Ministry of Higher Education in Saudi Arabia is the only institution that is responsible for public and private colleges and universities. The Ministry has offered unprecedented expansion of higher education since 2009. From 2009 to 2014, the number of public universities increased threefold. There are now 25 public universities in Saudi Arabia.

Males and females are segregated by sex in Saudi education. However, King Abdul-Aziz University of Science and Technology (KAUST), which focuses on research and technology, embraces coeducation; it is the only government educational institution that does so. In 2010, the Ministry of Education established a female public university: Noura University in Riyadh, which enrolls 40,000 female students.

Based on a political agreement between the United States of America and Saudi Arabia to increase the number of Saudi students in the USA, in 2005, the government of Saudi Arabia launched the largest scholarship in the country's history, the King Abdullah Scholarship Program (SACM, 2011). Since then, the Ministry of Higher 
Education has invested billions of dollars in educating Saudi males and females. These students have been sent to different parts of the world to develop their knowledge and skills. The number of Saudi students in the USA has increased dramatically. The Saudi Arabian Cultural Mission (SACM) in Washington issued statistics that showed that the number of Saudi students in American colleges and universities exceeded 100,000. Significantly, the king's program gives equal opportunity to males and females.

The Education Digest of UNESCO (2000) presented educational statistics from Arab states, including Saudi Arabia, that showed gender parity and growth in enrollment in schools that was much higher for women. The report also pointed out that if this trend continued, females would soon outnumber males in school enrollments in the region. Moreover, according to Human Development (UNDP) for 2014, Saudi Arabia has achieved 64\% in global development education, surpassing the average for global development in education.

\subsection{Identity, Voice, and Academic Writing}

Fernsten (2008) conducted a study to explore how students construct their identity through writing as this relates to cultural issues. The case study is of Mandy (pseudonym), a Korean-American student who was born in Korea and emigrated from Korea with her parents to the USA when she was young. The study concluded that Mandy's identity kept changing. She struggled to negotiate her identity between the American culture and traditional Korean culture. The study concluded that she experienced conflicts in power relationships and social capital, which played a significant role in constructing her identity.

Hsieh (2008) examined how seven international female Chinese students negotiated their identities in English (L2) in higher education in the USA. Qualitative methods were used in this study. One of the most important findings was that most of seven Chinese students experienced inconsistency in their identity. They fluctuated between their own identity (self-chosen identify) and the identity given to them from the outside. All participants struggled to construct a self-affirming identity rather than a social identity imposed on them by others. All participants reported that they experienced discouragement about becoming competent in navigating the host culture due to some Americans' considering American culture to be superior.

Nkaoko (2009) explored the roles of language, culture, and gender in an international graduate student (Kot'a, a male student) in socializing and participating in an academic setting. The study reported four areas where the participant struggled: comprehending the reading materials, understanding classroom discussions, stating his arguments, experiencing anxiety over feedback, and socializing with his peers outside the classroom. The study showed that these factors had a significant influence on constructing his identity. He felt alienated due to his limited language ability in English, his background, and what the participant described as a feminist-orientated setting.

Many research studies on identity have drawn their definitions of identity from the Russian linguist Mikhail Bakhtin's notion of heteroglossia, which refers to the influence of speech in one language on another, which can be described as affecting authorial intention (Ramthan \& Atkinson, 1999). Donald Stewart echoed this position by stating that written voice is our authentic voice or the "authorial voice, which sets you apart from every [other] living human being despite the common or shared experiences you have with many others" (Stewart, 1972; cited in Bowden, 1995, p. 175). Ivanic and Camop (2001) corroborated that voice, whether in speech or written form, refers to expressions of the writer's own views, authoritativeness, and authorial presence. Yancey (1994) defined voice as "one of the most frequent metaphors employed in rhetoric and composition" (p. vii). Bowden (1995) stated that voice "remains extraordinarily popular among American composition teachers and has a strong presence in contemporary classroom discussions of writing" (p. 173). Appleman (2001) considered "voice an engaging metaphor for human agency and identity" (p. 245). Because different people have defined the notion of voice differently, any discussion of it must be based on definition of voice that is considered and consistent. Elbow (1994) specified "five meanings of voice that are relevant to writing: (a) audible voice or intonation (the sounds in a text), (b) dramatic voice (the character or implied author in a text), (c) recognizable or distinctive voice, (d) voice with authority, and (e) resonant voice or presence" (p. xx).

Elbow (1994) defined subcategorizations that capture the essence of the term "voice" in various definitions. Previous studies have highlighted the significance of the concept voice in rhetoric, linguistics, and education. Most of these definitions have captured the meaning from the writer's lens. Very few have incorporated readers' perspectives. In this paper, however, the definition suggested by Ivanic and Camop (2001) was that "voice is often used to refer to expressions of the writer's own views, authoritativeness, and authorial presence, [which] provides the premises for framing discussions the subject in question" (p. 43).

Many research studies have explored the relationship between voice and academic writing (Ivanic \& Camps, 2002; Matsuda, 2001; Stapleton, 2002, 2003). Many researchers have argued that voice is irrelevant to academic 
writing and that the importance of voice has been overstated in professional literature (Helms-Park \& Stapleton, 2003; Stapleton, 2002). But Ivanic and Camps (2002) stressed that in writing, self-representation or voice is critical. They buttressed this position by investigating the writing of six graduate students in universities in the United Kingdom. Their study proposed seven types of voices: "a sexist voice, a progressive-educator voice, a positivist voice, a nonsexist voice, a self-assured voice, a deferential voice, a committed-to-plain-English voice, or a combination of an infinite number of such voices" (Stapleton, 2002). Paul Matsuda (2001) disagreed slightly from this view by arguing that voice is not only associated with the ideology of individualism, but also involves multiple individual and collaborative platforms. Matsuda (2001) used the notion of collectivist culture to examine a written discourse of a Japanese student and concluded that combinations of different discursive features were necessary tools in both the speech and writing of the participants.

Atkinson and Manathan (1999) viewed the argument differently by noting that the principal practices of L1-orientated composition that appear in mainstream education in the USA are based upon an "ideology of individualism, voice, peer review, critical thinking, and textual ownership, [which] are not in line with cultural approaches taken by ESL students" (p. 61). In response to their argument, Elbow (1999) critiqued their framing of the discussion of voice on their distinction between cultures. Elbow (1999) asserted: "The U.S. mainstream culture of communication values voice [and opposes] cultures (such as Asian or Native American cultures) that do not value voice or, as it were, value no voice" (p. 22).

Atkeson (2000) conducted a comparative empirical study between ESL students in a USA university and other nonnative writers. He concluded that some qualities inherent in nonnative writers also appear in ESL student writers. Both groups - the nonnative writer and the ESL student - show a lack of certain cultural abilities in their academic writing. Stephens (2002) argued that the importance of voice in second-language writing discourse is overestimated. He stated that such a position is misleading to second-language learners and instructors because they might think that the notion of voice is more important than generating ideas and building an argument. These studies demonstrate that writing, voice, and identity formation generate controversy among researchers, yet these three elements are fundamental gateways to understanding writing and identity formation among ESL students in the United States.

\subsection{Theoretical Framework}

This study aimed to explore how two female Saudi ESL students constructed their identity as writers as they mastered a second language, English, at an American university. The study also examined the challenges that female Saudi students encountered in acquiring English academic writing skills in an ESL milieu. In what follows, discuss the purpose of the study through focusing on the overarching theoretical framework of the study I delve into methods used in this study, the rationale for this method, and data collection. Participants, settings, Internal Review Board (IRB) issues, and other ethical issues will be discussed.

This study shed light on the discoursal construction of identity in academic writing in the life of female Saudi ESL students at a Western university. It focuses exclusively on how these women resisted, negotiated, and constructed their academic writing identity throughout their English language program. This study draws on critical theory (CT) as an overarching paradigm because it suits the nature of this investigation.

Qualitative researchers tend to use open-ended questions so that the participants can share their views (Creswell, 2014, p. 9). Bourdieu's (1986) form of capital provided the theoretical framework of this study.

Through the work of Bourdieu on forms of capital (1986), I discuss how the participants constructed their identity as writers. Bourdieu posited that the concept of capital is not limited to economic capital; there are three other forms of capital. The first concept is linguistic capital, which refers to the language or languages that the individual speaks, while the second concept is social capital: whom you know and social connections of the individual in society. The third concept is cultural capital: values, rules, and the individual's knowledge, codes, norms, and how an individual behaves in the society.

\section{Methodology}

This research had a threefold purpose. The first was to explore how two female Saudi ESL students constructed their identity as writers when learning a second language, English, in an American university. The second was to investigate the factors that affected these female Saudi students in their academic writing in an ESL context. The third was to shed light on the exercises of Saudi ESL learners to stimulate debate and at the same time call for the importance of studying second-language writing and identity issues.

\subsection{Research Questions}

This narrative-inquiry study aimed to answer the following research questions:

1) How do female Saudi students construct their writing identities in an American university? 
2) What are the challenges that face female Saudi students in writing in an American university?

\subsection{Setting}

The research was conducted in a diverse North American university in the Southwest of the United States. The university offers bachelor's, master's in many disciplines (e.g. TESOL), and PhD degrees in a wide range of subjects. There is an English-language initiation, which is not affiliated with the university; however, it accommodates most of the ESL international learners who intend to matriculate at the university. The research was carried out in the spring semester in 2015 and lasted four months.

\subsection{Participants}

The sample of this study was purposive samples of female Saudis studying in the university who had studied for at least six years in public or private schools in Saudi Arabia. There were two participants, aged 27 and 29. Both were unmarried female Saudi students studying in English language institute in the USA.

The participants were recruited by my distributing a flyer at the English institute. As far as screening is concerned, the researcher depended on the self-report of the participants regarding their demographical information. In the recruitment process, the participants were informed about the purpose of the study and were told that all the information pertaining to the study would be used only for research purposes.

Due to the religious and cultural principles, the participants were asked whether they preferred to be escorted by a chaperone during the interview. If they preferred to be accompanied by a chaperone, the researcher would ask the participants to bring a chaperone.

The following table gives a summary of background of both participants.

Table 1. Demographic characteristic of the participants

\begin{tabular}{rllllllll}
\hline Name & Age & Social Status & Major & $\begin{array}{l}\text { Level } \\
\text { Edu. }\end{array}$ & $\begin{array}{l}\text { of } \\
\text { Enevel of }\end{array}$ & $\begin{array}{l}\text { Years } \\
\text { studying English }\end{array}$ & $\begin{array}{l}\text { Years of Studying } \\
\text { in the USA }\end{array}$ \\
\hline Sarah & 29 & Bachelor & Nursing & MA & Level 5 & 11 & One \& a half \\
Fatimah & 27 & Bachelor & Nutrition & MA & Level 5 & 11 & 2 years \\
\hline
\end{tabular}

3.4 IRB

Institutional Review Board (IRB) protocol was followed throughout the study. In terms of the participants, of course there were consent letters to sign in both English and Arabic.

\subsection{Data Collection Method}

The essence of this project was to document international students' experiences in an ESL context, so data were collected from multiple sources at various time points during 2015. I collected the data by utilizing two methods. In an autobiographical narrative, the participants were given instructions to write an essay about their experience in learning English in the United States. They were also asked to turn in an essay about any topic of their choice that illustrates their learning experience in the USA. This method is appropriate for this investigation to capture the linguistic, cultural, and social experiences that participants went through. The suitability of using narrative inquiry in documenting human experiences as a tool has been unequivocally stated by Connelly and Clandinin (2000): "Narrative inquiry is a way of understanding experience. It is a collaboration between researcher and participants over time, in a place, or a series of places and social interaction milieus" (p. 139). The second method was a semi-structured interview chosen because this approach would generate deep and rich data (Rossman \& Rallis, 2012): "An interview is a generative way to get rich, detailed data about how people view their world" (p. 179). The data were recorded on a digital audio recorder and stored on my personal computer, which was password-protected.

The participants were interviewed individually once in the main university library, and each interview took about 90 minutes. The questions were designed to obtain responses to the aforementioned research questions. The first section of the interview questions incorporated questions to elicit participants' demographic information. The second section of the interview dealt with the first research question. In this section were questions designed to capture participants' writing experience in an ESL context. The third and last section of the interview as designed to investigate the challenges that participants encountered in writing English in an ESL setting. I asked both participants to write an autobiographical narrative about their experiences in learning English in an American university, particularly about their academic writing experiences. I transcribed the data verbatim. 
One of the problems with collecting data was the face-to-face communications with the participants because of the religious and cultural constraints. Due to religious and traditional principles, the female participants were asked to bring a chaperone of their choice. Moreover, the interviewer tackled issues that made the participants feel uncomfortable or stressed. Hence, the researcher informed the interviewee that they did not have to answer the question, or sometimes the researcher changed the topic into another subject or stopped the interview and rescheduled it.

\subsection{Analysis}

Drawing on qualitative data analysis, I analyzed the data based on this framework: "Analysis is shaped by the genre framing your study" (Rossman \& Rallis, 2012, p. 271). The approaches utilized in collecting data had a significant impact on the analysis. I followed the eight phases proposed by Rossman and Rallis: 1. organizing the data, 2. familiarizing the researcher with the data, 3. identifying categories, 4. coding the data, 5. generating themes, 6. interpreting, 7. searching for an alternative understanding, and 8. writing the report. After each interview, I transcribed the data immediately and started analyzing the data. "Analysis starts before you collect data; you have to have some ideas about what you are going to study and continues throughout the research efforts" (Bernard \& Gery, 2000). Some parts in the interview were conducted in Arabic, so I translated them into English and transcribed them. Then, I read the scripts many times during the coding. I also translated some parts of the autobiographical narratives. Then, I used a color coding approach by applying certain approaches such as repetition: Anyone who has learned long stretches of talk "knows how frequently people circle through the same network of ideas" (Bernard \& Gery, 2000).

After coding the data for the second cycle, I categorized themes based on frequency, similarities, differences, transitions, and language connectors. Various themes emerged from the data. The most important themes that emerged from the data were: frustration, negative perceptions of EFL experience, and communicative competence issues. Based on the two main research questions of this study, I reached conclusions that address and answered the research questions.

\section{Findings/Results}

\subsection{Major Theme}

Many themes emerged from the data from the semi-structure interviews and autobiographical narratives. The most important themes that emerged were frustration and negative perception that both participants expressed regarding their previous English learning experiences in Saudi Arabia (EFL).

Sarah (pseudonym), studied English for 11 years in Saudi Arabia (EFL), 6 years in public schools and 5 years in college studying nursing. She stated in the following excerpt that after 11 years of studying English, she still felt linguistically incompetent. She also expressed her negative perception of the traditional instructions in an EFL context.

"Aha. It's bad because I finish the high school and I couldn't speak English or write. Um I don't understand a lot of things in English. Um it's just focusing in gramma-the grammar. So ah ah I consider myself have a zero knowledge in English but ahhh when I went to the university I learn a lot because we study a lot things all our classes in English we contact with doctors and English speakers in the hospital."

Sarah added in another part of the interview that cultural competency was a great challenge in academic writing. For instance, she narrated that she was confused about how to build her argument about certain issues that were unfamiliar and contradicted her faith, such as gay marriage. Her cultural incompetence and fear that her teacher judged her because of her opinion hindered her from honestly expressing her views. Therefore, she tried to soften those and choose her words carefully.

The Forms of Capital (Bourdieu, 1986), are linguistic capital, cultural capital, and social capital. The participant response here reflects certain forms of linguistic capital. The text refers to her previous EFL experience as a form of linguistic capital, so she expressed her enthusiasm and achievement in communicating with doctors in a hospital in her basic L2 skills:

"Yeah sure by um... writing um... ah... um... the opinion essay about gay marriage and it's difficult for me because I don't understand the teacher will judge my paper because I have um... my um ... principles from my religion and my culture and here it's different so I write it and I try to make it nice to um... but then the teacher told us you have to write your opinion um... not like this write what you want and it's your opinion so then after that when we talk about this topic, I understand that people here respect your opinion so I can write". 
On another similar topic, Sarah reported that writing about religion was a big challenge. For instance, she expressed her unwillingness to discuss these issues because of her fear that the instructors or her peers would misunderstand her perspective. She stated:

"ah... I tried to use like nice words and I don't wanna talk about the um... topic in our religion so I don't wanna people make bad or get bad idea about my religion so um ... that's it".

In responding in one of the follow-up questions, Sarah reported that apprehension towards her teacher and peers' judgment caused her a lot of frustration, especially when she repeatedly clarified her ideas about her religion or culture.

"Yeah. Ah the people or the students specially ask you about wrong ideas that they have about your country, and you try to explain to them, um and they still have the same idea....um that's make me ah um (long pause) UNCOMFORTABLE, ah talk about the same thing again, so um also some topics that the teachers talks about it, we can't share and we can't talk about it because you don't want other students from your country judge you and have um ah .... a bad idea about you".

Sarah responded to a question about identity and defined herself through association with two worlds. In spite of all the challenges she faced, she was proud to engage in her postgraduate studies in the USA. She also felt proud to be labeled as an instructor in a university in Saudi Arabia after she graduated. She stated:

“OK. I'm Sarah, I'm an English learner student from Saudi Arabia umm I'm proud to study MA degree here and umm I'm proud to get a job in university after I graduate immediately umm that's it"

Sarah narrated that she encountered some challenges in learning academic writing. For example, she could not get corrective feedback from her teacher or anyone in the class. Consequently, she had negative perceptions because she could not improve her academic writing.

"umm ... I think um... when I was in San Antonio um... the book because ah... they choose bad book to, it's difficult to understand ah... how you should write and... here I think the challenge the teacher didn't have enough time for each student to focus in his or her problem, so my problem in writing is the spelling to and the make my sentence more improve so when I ask the teacher she said ok we will explain that later and umm I didn't find someone to tell me how to improve this problem or how to fix this problem".

By the same token, Fatimah, who studied English for 11 years in Saudi Arabia, six years in public schools and five years studying clinical nutrition in college, expressed her frustration around her EFL journey. In the following excerpt she shared her previous experience in learning English in Saudi Arabia and expressed her distress and said,

"um ...I will tell you whatever I remember. At that time when I studied English in Saudi Arabia there was no focus on language components...um like writing ...reading ... They only focus on test ...its all about tests. They gave us the tests questions and they ...um teach us how to do in the tests......It means that they (English teachers in SA) worked hard not make us freak out... in terms of compositions.... um teacher used to give us certain essays to focus on and memorize so we can write in the test. Um aha the teachers used to explain and teach English by using Arabic...I only remember when of my teacher in the high school was teaching us by using English only. um...so, we were not allowed to communicate in Arabic in the classroom".

In the following excerpt from her biography, Fatimah shared her story when she first arrived in the USA. She narrated that she struggled in communicating with people because of her frustration about using English, as well as her fears that people would ridicule her language deficiencies.

"First, I hardly spoke any English so everything was very difficult for me. Getting around, shopping, travelling, or even going to school was so hard. I was also very shy to speak to anybody because I thought people would make fun of my language".

Sarah described that English played a crucial role in her life in general and in professional contexts in particular. She expressed her imagined identity in the future and explained how learning academic writing might change her life.

"Yeah I think that if I become a good writer, that would be great and I will get benefit....um ah first of I will feel much better when people read my writing and understand me well. ....also...in the future I need writing ...I will be working in a hospital um I should write correctly when I diagnose my client...so that would be good for me and for the readers." 
Fatimah expressed her views about writing about sensitive topics. She shared an experience in one of the writing classes when she was asked about what she thinks of the Islamic State in Iraq and Syria (ISIS), she preferred to keep silent. That silence could be interpreted as fear of judgment or her cultural incompetency that she could construct her voice without any conservatives.

"Well... I don't remember..um oh yeah..once the teacher brought us an article about ISIS (Islamic State in Iraq and Syria). Yeah and he asked us for our opinion about ISIS...um yeah. I didn't say my opinion ... yeah".

In responding to a similar question, Fatimah explained how she would construct her voice regarding sensitive topics; however, she emphasized that she would say everything nicely. Fatimah adopted and used similar strategies to Sarah's to express her opinions. Instead of expressing her voice unreservedly, she felt that she was in an unsafe zone, and her opinion might offend her instructor or her peers; therefore, she preferred to soften her language. Her cultural incompetency deterred her from constructing her voice naturally.

"Well. I will say my opinion but I would say my opinion and I would state the Islamic perspectives but I would say it nicely I don't want offend anybody".

Responding to questions regarding the role of Hijab (the veil) and whether it had any an impact on her learning English or socializing with people to improve her English and any other activities, she stated that she was not sure whether it had negative or positive impact on her learning. She explained that she has limited communications with people in her time in the university.

"I will tell you my case and you decide if this impact positive or negative....um (long pause)...um in my case.....um The time that I spend in the university is the only time that I could invest in improving my English... spend my time in the university...so I could work on my weakness points and try to develop my language... But once I got back home I can't go out ... because I don't drive....so when I am home I depend on social media in communicating and improving my English".

Regarding how Fatimah constructed her voice in English and Arabic, she stated that she was not used to stating her opinion; however, she thought that this would be easier in Arabic than in English.

"um ah. I don't know but it seems difficult to construct my voice ...I don't know how ...even in Arabic I don't think I have construct my voice but I'm sure it would be easy in Arabic than English".

Responding to a question about how Fatimah identified herself, she refused to answer the question. That could be an embarrassing question to be answered in presence of her chaperone. Nevertheless, in responding to a similar question, she stated her imagined identity in the future and associated herself to the profession of nutrition specialist. She also talked about quality issues, about a "renowned hospital," and it seemed that she liked constructing this imagined identity.

"ah um I want to be a nutrition specialist...ah ......in a renowned hospital and I wish to be famous so people will know me as an excellent n nutrition specialist".

Likewise, Fatimah reported in her autobiography that the more she became linguistically competent, the more she gained self-esteem and self-efficacy. She also associated her improvement in language with both her life and her future plans. The possible explanation of this change in her perceptions was due to the fact that Fatimah constructed her identity, particularly her imagined identity with her language proficiency.

"Month after month, and as my English language skills became stronger, I finally started gaining grounds and became more confident about my conversational English. I started loving my school because I sensed progress and improvement after every exercise and assignment and that kept me alive. Now, I am looking forward to completing all my ESL requirements and getting enrolled in a competitive and reputable school so that I can be ready for the next step!"

\section{Discussion}

The results of this study indicated that both participants believed that English played a crucial role in their life in general and their professional ones in particular. For instance, Sarah reported the significance of academic writing and explained how learning academic writing skills empowered her in her professional life. In the same way, Fatimah reported that academic writing would open the door for her to get a decent job in the future. Both participants associated mastering academic writing skills with their dreams and goals. Therefore, I argue that academic writing has a positive impact on participants' perceptions. As the result of that, both participants negotiated and constructed their imagined identities through academic writing. This finding is consistent with 
that of Yamani (2000), who found that "proficiency in spoken and written English becomes a status symbol, a marker for the ability of obtain private education and travel abroad, and a sign of cosmopolitan lifestyle" (p. 58).

Bourdieu (1986) discussed forms of capital: linguistic capital, cultural capital, and social capital. Both participants' responses reflected certain forms of linguistic capital. The texts referred to their previous EFL experiences as manifestations of forms of linguistic capital that both participants lacked. To the contrary, Sarah expressed her enthusiasm and achievement in communicating with doctors in a hospital using her basic L2 skills and how that practice built her confidence. A possible explanation for this result may be a lack of an adequate form of linguistic capital. As a result of that, both participants put a lot of effort into learning English writing to get the privileges of speaking English in Saudi Arabia to acquire linguistic capital.

In these texts, as well as in the bibliographies, they both reported learning English in general and writing skills in particular as a route to success in society. Therefore, this result showed that both participants constructed their future identity based on learning English writing. They were seeking to gain cultural capital through learning writing skills, so various strategies were used to construct their voices. Although the participants felt unsafe about constructing their honest opinion about cultural issues and sensitive topics, both participants tried to negotiate and use different strategies to construct their voices through compromising and using soft words.

Both participants reported their awareness of their metalinguistic skills, so the results revealed strong evidence that both participants were conscious that they lived in two different worlds when they express themselves in Arabic or English. They constructed different identities when they express themselves in English. In her narrative, Sarah demonstrated her prior experience, which made her feel confident to evaluate books. She displayed self-efficacy by her judgments on books. Social capital in this context played out as an asset to the participant who believed that she had good communication skills that were not employed by the teacher herself.

\section{Conclusion and Implications}

The findings should have important implications for developing teaching strategies that ESL teachers could use with female Saudi ESL learners in academic writing classes. For example, the findings of the study suggest that ESL programs addressed to female Saudis should embrace various cultural activities and expose the female Saudi students to different people and different cultures to augment their cultural competency. Moreover, the findings suggest that ESL instructors should focus on exploring female Saudi students' issues to help them to improve their writing skills. ESL instructors should create a secure atmosphere in the ESL classroom to encourage female Saudi students to express their own voices. This recommendation supports the idea of Canagarjah's safe house; he suggested that "minority students in an academic setting [should] employ some of the same strategies, including constructing 'safe houses' to resolve some of the conflicts [that] they face." He further suggested that "identifying and understanding the literate activities of safe-house spaces opens up pedagogical possibilities inside and outside those spaces" (Canagarjah, 1997, p. 122). In general, therefore, it seems that increasing teacher awareness of the learner's background and culture is imperative. The findings of this study would also prove beneficial in academic writing issues in the ESL milieu.

This study also raised implications about multiculturalism in the context of higher education in the United States. Many of the people quick to accuse others of Islamophobia may be unaware of their own lack of understanding of and respect for Islamic cultures, ideas, and values - in this case, the historical and political context of the Kingdom of Saudi Arabia. These people may gladly welcome Muslim women from Saudi Arabia into graduate programs in the U.S. but remain uncomfortable about enduring cultural differences between the United States and the Kingdom of Saudi Arabia. As this paper has demonstrated, Saudi Arabia has supported equal access to scholarships for Saudi men and Saudi women to pursue higher education abroad, but many Americans may not be aware of this fact and may look at the Saudi system of separate education for men and women as sexist - perhaps viewing this through the lens of the many decades (more than half a century) in the United States in which education (and many other institutions of public life) were segregated by race under the "separate but equal" doctrine, in which racially segregated education in the South was held not to violate the equal protection clause of the Fourteenth Amendment - until that was overturned by Brown v. Board of Education (1954), which eventually led to eliminating racial segregation in public education. Do Americans see segregation of men and women in education in Saudi Arabia through the lens of the history of racial segregation in the United States?

Are the people who embrace multiculturalism in the United States and welcome female Saudi students in graduate-school classrooms truly respect and honor the women from Saudi Arabia who uphold what some refer to as traditional family values, as in discomfort with or disagreement with the institution of same-sex marriage. I argue that people do not have to be the same to be equal, but in fact, do students in graduate school in the United 
States have to uphold the same political ideology and cultural values to be treated as equals? The female Saudi students in this study did not feel comfortable speaking openly about their views towards culturally sensitive issues because these issues opposed with their religion and beliefs. They did not wish to offend others or to engage in controversy. But are all who talk the talk of multiculturalism truly ready to walk the walk of multiculturalism by acknowledging and accepting that different countries and different cultures have the right to live in accordance with their own traditions and ways of structuring society? So, I think that intolerance may take many forms. Perhaps there is legitimacy in Americans' viewing the Saudis as being sexist for segregating education with separate institutions for boys and girls, men and women or as being homophobic for disapproving of same- sex marriage marriage. However, perhaps there is legitimacy in Saudis' viewing Americans as being intolerant for disapproving of segregating education by sex and of disapproving some culturally sensitive issues such as same-sex marriage. If people from different cultures must pretend to share the same views and opinions, is that true multiculturalism? Or is that a form of cultural chauvinism and intolerance? Discussing these issues openly may make some people uncomfortable. The female Saudi students interviewed in this research were perceptive enough to figure that out. Listening with respect to people who hold different views, however difficult, seems to be essential to establish a truly multicultural classroom.

\section{References}

Block, D. (2007b). Second language identities. London: Continuum.

Bourdieu P. (1986). The forms of capital. In Szeman, I. \& Kaposy, T. (Eds.), Cultural theory: An anthology (pp. 81-93). Oxford: John Wiley \& Sons.

Canagarajah, A. S. (1997). Safe Houses in the Contact Zone: Coping Strategies of African-American Students in the Academy. College Composition and Communication, 48(2), 173. https://doi.org/10.2307/358665

Canagarajah, A. S. (2015). "Blessed in my own way": Pedagogical affordances for dialogical voice construction in multilingual student writing. Journal of Second Language Writing, 27, 122-139. https://doi.org/10.1016/j.jslw.2014.09.001

Chamcharatsri, P. (Bee). (2010). Problematizing Identity: Everyday struggles in language, culture, and education, by Lin, A. M. Y. Journal of Language, Identity \& Education, 9(1), 87-89. https://doi.org/10.1080/15348450903476873

Clandinin, D. J., \& Connelly, F. M. (1996). A storied landscape as a context for teacher knowledge In M. Kompf, D. Bond, D. Dworet, \& R. Boak (Eds.), Changing research and practice: Teachers' professionalism, identities and knowledge (pp. 137-148). London: Falmer. https://doi.org/10.1201/9781315043227-15

Duff, P. A. (2001). Language, Literacy, Content, and (Pop) Culture: Challenges for ESL Students in Mainstream Courses. Canadian Modern Language Review, 58(1), 103-132. https://doi.org/10.3138/cmlr.58.1.103

Elbow, P. (1994). What do we mean when we talk about voice in texts? In K. B. Yancey (Ed.), Voices on voice (pp. 1-35). Urbana, IL: National Council of Teachers of English.

Fernsten, L. A. (2008). Writer Identity and ESL Learners. Journal of Adolescent \& Adult Literacy, 52(1), 44-52. https://doi.org/10.1598/JAAL.52.1.5

Handley, K., Sturdy, A., Fincham, R., \& Clark, T. A. (2006). Within and Beyond Communities of Practice: Making Sense of Learning Through Participation, Identity and Practice. Journal of Management Studies, 43(3), 641-653. https://doi.org/10.1111/j.1467-6486.2006.00605.x

Hsieh, M. H. (2006). Identity negotiation among female Chinese international students in second-language higher education. College Student Journal, 40(4), 870-885.

Ivanič, R. (1994). I is for interpersonal: Discoursal construction of writer identities and the teaching of writing. Linguistics and Education, 6(1), 3-15. https://doi.org/10.1016/0898-5898(94)90018-3

Jabur, Z. M. (2008). A qualitative study of Omani Muslim women's perceived experiences as writers in English as a second language. (Doctoral dissertation, Indiana University of Pennsylvania).

Kim, H. Y. (2011). International graduate students' difficulties: Graduate classes as a community of practices. Teaching in Higher Education, 16(3), 281-292. https://doi.org/10.1080/13562517.2010.524922

Kingdom of Saudi Arabia Ministry of Health. (2013). The Statistical Yearbook for 1434 AH (2013 AD). Retrieved from https://www.cdsi.gov.sa/yb49/Pages/MixPageOne.htm

Matsuda, P. K. (2001). Voice in Japanese written discourse. Journal of Second Language Writing, 10(1-2), 35-53. https://doi.org/10.1016/S1060-3743(00)00036-9 
Matsuda, P. K., \& Tardy, C. M. (2007). Voice in academic writing: The rhetorical construction of author identity in blind manuscript review. English for Specific Purposes, 26(2), 235-249. https://doi.org/10.1016/j.esp.2006.10.001

Morita, N. (2004). Negotiating Participation and Identity in Second Language Academic Communities. TESOL Quarterly, 38(4), 573. https://doi.org/10.2307/3588281

Norton, B. (2018). Language, identity, and the ownership of English. TESOL quarterly, 31(3), 409-429. https://doi.org/10.1002/9781118784235.eelt0030

Rahman, M. S. (2017). The advantages and disadvantages of using qualitative and quantitative approaches and methods in language "testing and assessment" research: A literature review. Journal of Education and Learning, 6(1), 102-112. https://doi.org/10.5539/jel.v6n1p102

Rossman, G. B., \& Rallis, S. F. (2016). An introduction to qualitative research: Learning in the field. Sage Publications. https://doi.org/10.4135/9781071802694

Ryan, G. W., \& Bernard, H. R. (2000). Techniques to identify themes in qualitative data. Handbook of Qualitative Research. 2nd ed. Thousand Oaks, CA: Sage Publications.

Samimy, K., Kim, S., AH Lee, J., \& Kasai, M. (2011). A Participative Inquiry in a TESOL Program: Development of Three NNES Graduate Students' Legitimate Peripheral Participation to Fuller Participation. The Modern Language Journal, 95(4), 558-574. https://doi.org/10.1111/j.1540-4781.2011.01247.x

Schaafsma, D., \& Vinz, R. (2011). On Narrative Inquiry: Approaches to Language and Literacy (An NCRLL Volume). Language \& Literacy Series. NCRLL Series. Teachers College Press. 1234 Amsterdam Avenue, New York, NY 10027.

Sperling, M., Appleman, D., Gilyard, K., \& Freedman, S. (2011). Voice in the Context of Literacy Studies. Reading Research Quarterly, 46(1), 70-84. https://doi.org/10.1598/RRQ.46.1.4

Tardy, C. M. (2012). Voice construction, assessment, and extra-textual identity. Research in the Teaching of English, 47(1), 64-99.

Yamani, M., Royal Institute of International Affairs (GB), \& Middle East Programme. (2000). Changed identities: The challenge of the new generation in Saudi Arabia. London: Royal Institute of International Affairs.

\section{Copyrights}

Copyright for this article is retained by the author(s), with first publication rights granted to the journal.

This is an open-access article distributed under the terms and conditions of the Creative Commons Attribution license (http://creativecommons.org/licenses/by/4.0/). 